The 1966 New Delhi Conference did achieve perhaps most of its purposes at the meeting itself. This was novel internationally, in being a "work" meeting of seminars and small group discussions. However, many of its features had lessons for a wider public which are to be found in the above publications.

The organizers of our conference by their action thus followed the principle advocated by Dr. Pyke of resisting automatic publication of proceedings in expensive independent books of little or no permanent interest and usually destined for obscurity on a few library shelves. May the organizers of all conferences and similar meetings respond to his appeal.-I am, etc.,

H. S. Gear, Proceedings of Third World Conference

Faculty of Medicine,
University of Toronto,

Canada

\section{Hazard of Immunosuppressive Therapy}

SIR,-There is considerable evidence that immunosuppressive therapy may be associated with a higher incidence of cancer. ${ }^{1}$ The use of immunosuppressive drugs in the treatment of non-malignant conditions, without organ transplantations, has been reported in association with cancer in one case only. ${ }^{2}$ We present here the case history of a patient with systemic lupus erythematosus (S.L.E.), in whom malignant melanoma was diagnosed 6 and 2 years after starting treatment with prednisone and azathioprine respectively.

A woman aged 41 had started to suffer from arthritis, fever, nausea, and fatigue in 1965 , and developed a generalized erythematous rash. Investigations led to a diagnosis of S.L.E. and her symptoms and signs were controlled by $60 \mathrm{mg}$ prednisone daily. During the next 4 years she felt well except for symptoms of hypercorticism while she was on 10-35 mg prednisone daily. She was readmitted on three occasions for exacerbations of her symptoms and treated with larger doses of steroids. In 1969 she again developed fever, arthritis, a skin rash, and Raynaud's phenomena with a positive L. E. test. Proteinuria, 2-3 g daily, was noted for the first time. Creatinine clearance was $80 \mathrm{ml} / \mathrm{min}$. Since the patient objected to treatment with higher doses of steroids, she was given a combination of $20 \mathrm{mg}$ prednisone and $200 \mathrm{mg}$ azathioprine daily. This resulted in a disappearance of the proteinuria and the other signs of active S.L.E. The patient remained asymptomatic for the following 12 months, during which repeated L.E. preparations were negative and the white blood cell count fluctuated between 3,500 and 5,500 per $\mathrm{mm}^{3}$.

In January 1971, while on $10 \mathrm{mg}$ prednisone and $100 \mathrm{mg}$ azathioprine daily, proteinuria reappeared. Five months later she had a recurrent bout of fever, arthralgia, and skin rash. In addition to increased sedimentation rate, positive antinuclear factor, and L.E. test, she had moderate anaemia and a positive direct Coomb's test. Protein excretion in the urine reached $5 \mathrm{~g}$ daily. A kidney biopsy showed changes compatible with active lupus glomerulonephritis. The patient was given $150 \mathrm{mg}$ azathioprine and $30 \mathrm{mg}$ prednisone daily; her symptoms subsided and the L.E. test became negative again. However, despite subjective improvement, proteinuria increased to $7 \mathrm{~g}$ daily; creatinine clearance decreased to $62 \mathrm{ml} / \mathrm{min}$, serum albumin dropped to $2.5 \mathrm{~g} / 100 \mathrm{ml}$, and blood cholesterol increased to $510 \mathrm{mg} / 100$ $\mathrm{ml}$. In October 1971, azathioprine was substituted by $200 \mathrm{mg}$ cyclophosphamide daily, and 2 months later the dosage of prednisone was increased to $50 \mathrm{mg}$ daily, without any effect on the proteinurea or the kidney function.

In December 1971, the patient reported a marked enlargement of a pigmented naevus on the dorsum of her right foot. Examination revealed an irregularly pigmented hairless naevus, slightly protruding above the skin There was no regional or generalized lympadenopathy. Histological examination of the excised lesion revealed a superficial malignant melanoma. No malignant changes were found in biopsy specimens taken from two other pigmented naevi.

Considering the progression of the nephrotic syndrome despite immunosuppressive therapy, cyclophosphamide was discontinued. The patient is at present on steroids, and the proteinuria fluctuates between 3 and $5 \mathrm{~g}$ daily.

Chance association between S.L.E. and malignant melanoma cannot be excluded in this patient. The S.L.E. could itself have predisposed to malignancy. There are severa reports describing neoplasms, mostly lymphomas, in patients with S.L.E. ${ }^{3}$ Further, it has been suggested that cancer results from a breakdown in the immunological surveillance mechanisms of the host, with a subsequent proliferation of an abnormal clone of cells. ${ }^{1}$ This hypothesis is supported by the finding that cell mediated immunity may prevent or delay the onset of virus induced malignancy in animals ${ }^{4}$ and by the higher incidence of lymphorecticular neoplasms in patients with immunological deficiency states 1 and on immunosuppressive therapy for organ transplant. ${ }^{5}$ Malignant melanoma is among the few human neoplasms against which an immunological hos reaction has been shown to occur. ${ }^{6}$ Therefore, the possibility that the developmen of the neoplasm in this patient was related to the treatment with azathioprine should be borne in mind, even though malignan melanoma has not been so far described in association with immunosuppressive therapy. -We are, etc.

N. ManNy

E. Rosenman

J. BENBASSAT

Departments of Medicine A, and Hematology,

Hadassah University Hospital,

Jerusalem, Israel

1 Keast, D, Lancet, 1970, 2, 710

Doll, R., and Kinlen, L., British Medical Fournal, Calabro, J. J., Arthritis and Rheumatism, 1967, 10,553. A. C., British Medical Fournal, 1970, 4, Allison, A. C., British Medical fournal, 1970, 4, Penn. I., Hammond, W., and Brettschneider, $L$. and Starzel. T. E., Transplantation Proceedings Morton.' D. L., Holmes, E. C., Eiber, F. R.,
and W ood. 1971, 74, 587

\section{Diagnostic Abdominal Paracentesis}

SIR,-As a comment on the article by Dr. J. Gjessing and others (4 March. p. 617) I can state that a four-quadrant tap with a sharp needle has found favour in at least one surgical centre. It will be interesting and instructive to see if other centres state their views and to know if they will find this technique as valuable as we do. The usefulness of the four-quadrant tap can be ummarized as follows.

(1) The technique can be used at the bedside as part of the clinical examination, with the use of disposable needles and syringes, and repeated if necessary. Time taken is less than three minutes.

(2) There appears to be no recorded instance of peritonitis following puncture of the bowel by the needle, even in the presence of ileus. We have punctured the bowel on 10 occasions, with no ill effects.

(3) The technique will almost always detect amounts of free fluid in an excess of $200 \mathrm{ml}$ and allow its nature to be determined.

We have found the method so helpful and risk-free that we continued to use it and have reported our first cases. ${ }^{1}$

While not denying that the method of Dr. Gjessing and colleagues is likely to detect a smaller amount of free fluid than the four-quadrant tap, the use of the former relatively complex procedure as a routine initial measure when abdominal paracentesis is indicated seems to us to be wrong. $\mathrm{Dr}$ Gjessing's technique, I feel, will find its usefulness in cases where the clinical and other evidence strongly suggests the presence of free fluid but where the routine fourquadrant tap (repeated if necessary) is negative.-I am, etc.,

SEAN F. O BEIRN

University College and Regional Hospital, Galway

1 Mina, A. G., and O Beirn, S. F., Fournal of the

\section{Payment by Colour}

SIR,-Dr. Susan Dowling (11 March, p. 689) has once again highlighted the inequity of the differential salary scale for doctors (white and non-white) that exists in South Africa. Unfortunately, Dr. Dowling did not mention that the medical profession in South Africa is as concerned with the discrimination as she is. The Medical Association of South Africa has expressed its opposition to a differential salary scale on more than one occasion, and the Board of the Faculty of Medicine of the University of Natal has been equally opposed to this state of affairs.

As an opponent of South African Government policy and a member of the senior visiting consultant staff of King Edward VIII Hospital, Durban, I feel that Dr. Dowling has suggested the wrong line of approach to improving the existing situation. I am not afraid " for reasons of survival in that police state" to speak out, but the situation is that if the British Medical fournal does not advertise posts at hospitals and universities in South Africa the ultimate good of the patients is likely to suffer owing to the imposition of academic isolation. I do not believe that the policy of the B.M.A. and B.M.F. is inconsistent towards South Africa because it advertises institutional appointments in that country.

Dr. Dowling is correct in stating that medical manpower and facilities available to black South Africa are stretched to the limits and this applies equally in Government institutions and mission hospitals. As a member of the board of the McCord Zulu Hospital, a large mission hospital in Durban, I can state that if we could not advertise abroad it would be extremely difficult to 